\title{
Tetraenoic Species Are Conserved in Muscarinically Enhanced Inositide Turnover
}

\author{
Lucio A. A. Van Rooijen, Amiya K. Hajra, and Bernard W. Agranoff \\ Neuroscience Building, Mental Health Research Institute and Department of Biological Chemistry, The University of \\ Michigan, Ann Arbor, Michigan, U.S.A.
}

\begin{abstract}
Carbamylcholine enhances the labeling of phosphatidate and phosphatidylinositol from ${ }^{32} \mathrm{P}_{\mathrm{i}}$ in nerve endings. Approximately $74 \%$ of labeled phosphatidate and $85 \%$ of labeled phosphatidylinositol produced on muscarinic stimulation are accounted for by tetraenoic species, as detected by argentation TLC. Incubation of membranes derived from nerve endings with $\left[\gamma-{ }^{32} \mathrm{P}\right] \mathrm{ATP}$ under conditions of phosphodiesteratic degradation of endogenous polyphosphoinositides resulted in increased labeling of phosphatidate. Approximately $78 \%$ of the newly
\end{abstract}

formed phosphatidate was in a tetraenoic fraction. It is concluded that in muscarinically stimulated nerve endings, the diacylglycerol moiety is conserved following diacylglycerol release from polyphosphoinositides through its resynthesis to inositol lipid via phosphatidate. Key Words: Diacylglycerol-Inositol lipids-Muscarinic receptor - Nerve endings - Polyphosphoinositides-Tetraenoic lipids. Van Rooijen L. A. A. et al. Tetraenoic species are conserved in muscarinically enhanced inositide turnover. J. Neurochem. 44, 540-543 (1985).
The ligand-induced enhanced labeling of phosphatidylinositol (PI) and phosphatidate (PA) is believed to reflect a cycle that is initiated by the breakdown of phosphatidylinositol 4,5-bisphosphate $\left(\mathrm{PIP}_{2}\right)$ to diacylglycerol (DG) and inositol 1,4,5-trisphosphate $\left(\mathrm{IP}_{3}\right)$. The released $\mathrm{DG}$ is phosphorylated to $P A$ and is eventually converted back to $\mathrm{PIP}_{2}$ via CDP-DG, PI, and phosphatidylinositol 4-phosphate (PIP) as sequential intermediates (Berridge, 1983; Fisher et al., 1984). The often observed stimulated labeling of PA and PI can thus be viewed as a reflection of the restorative phase in an inositide cycle.

The enrichment in arachidonate of the inositol lipids (Kerr and Read, 1963; Keough et al., 1972; Marion and Wolfe, 1979) has led to the suggestion that one or more of the lipids of the inositide cycle serves as a reservoir from which arachidonate is released following stimulation of lipid turnover. Although arachidonate release from DG or $P A$ in thrombin-stimulated platelets has been reported (Bell et al., 1979; Rittenhouse-Simmons, 1980;
Billah et al., 1981; Lapetina et al., 1981), it has also been claimed that the 1-stearoyl, 2-arachidonoyl-snglycerol moiety common to inositol lipids is conserved under conditions of platelet activation (Broekman et al.. 1980, 1981). When pancreas slices are stimulated, the released DG is not primarily of the tetraenoic species (Banschbach et al., 1981). In studies on both stimulated platelets and pancreas, observed lipid changes related to the ligand-receptor interaction may be complicated by associated secretory events with their attendant changes in lipid turnover and composition. It was therefore of interest to investigate the possibility that the diglyceride moiety is broken down in a system that supports stimulated phospholipid turnover in the presence of ligand, but in which no known exocytotic secretion occurs. The muscarinically stimulated nerve ending preparation serves such a purpose. This preparation is of additional interest because of the putative role of arachidonate metabolites in neural function (Wolfe, 1982). It is known, in fact, that convulsions induce the release
Received April 25, 1984; accepted July 23, 1984

Address correspondence and reprint requests to Bernard $W$. Agranoff, Neuroscience Building, Mental Health Research Institute and Department of Biological Chemistry, The University of Michigan, 1103 E. Huron, Ann Arbor, MI 48109, U.S.A.

The present address of Lucio A. A. Van Rooijen is Neurobjology Department, Troponwerke, Berliner Str. 156, 5000 Cologne 80, F.R.G.
Abbreviations used: Atr, Atropine; $\mathrm{CCh}$, Carbamylcholine; DG, Diacylglycerol; HEPES, $N$-2-Hydroxyethylpiperazine- $N^{\prime}$ 2-ethanesulfonic acid; $I P_{2}, D-m y o$-Inositol 1,4-bisphosphate; $I P_{3}$, D-myo-Inositol 1,4,5-trisphosphate; PA, Phosphatidate; PI, Phosphatidylinositol; PIP, Phosphatidylinositol 4-phosphate; PIP $_{2}$, Phosphatidylinositol 4,5-bisphosphate. 
of free arachidonate in brain (Bazan, 1970), and that postdecapitation ischemia results in increased levels of 1-stearoyl,2-arachidonoyl DG in brain (Aveldano and Bazan, 1975).

\section{MATERIALS AND METHODS}

\section{Preparation and incubation of nerve endings and membranes}

Nerve endings were prepared from guinea pig cerebral cortex (Buckberg Lab Animals, Tomkins Cove, NY) by differential and sucrose gradient centrifugation (Van Rooijen et al., 1983). Nerve endings $(0.8-1.0 \mathrm{mg} / \mathrm{ml}$ of protein) were incubated with $30 \mu \mathrm{Ci}$ of ${ }^{32} \mathrm{P}_{\mathrm{i}}$ (Amersham, carrier-free) for $30 \mathrm{~min}$ at $37^{\circ} \mathrm{C}$ in $0.5 \mathrm{ml}$ of buffer $\mathrm{A}: 30$ $\mathrm{m} M \quad N$-2-hydroxypiperazine- $N^{\prime}$-2-ethanesulfonic acid (HEPES)/ $/ \mathrm{NaOH}(\mathrm{pH} 7.4)$ containing $142 \mathrm{mM} \mathrm{NaCl}, 5.6$ $\mathrm{m} M \mathrm{KCl}, 1 \mathrm{~m} M \mathrm{MgCl}_{2}, 2.2 \mathrm{mM} \mathrm{CaCl}_{2}, 3.6 \mathrm{~m} M \mathrm{NaHCO}_{3}$, and $5.6 \mathrm{mM}$ glucose. In experiments with prelabeled membranes, nerve endings were incubated either with 1 $\mathrm{mCi}$ of $\left[2-{ }^{3} \mathrm{H}\right] \mathrm{glycerol}$ (New England Nuclear, $500 \mathrm{Ci} / \mathrm{mol}$ ) for $90 \mathrm{~min}$, or with 2-3 $\mathrm{mCi}$ of ${ }^{32} \mathrm{P}_{\mathrm{i}}$ for $60 \mathrm{~min}$. Membranes were prepared by sequential freezing and thawing and subsequent washing of nerve endings (Van Rooijen et al., $1983)$. Membranes $(0.4-0.8 \mathrm{mg} / \mathrm{ml}$ of protein) were incubated at $37^{\circ} \mathrm{C}$ in air with shaking, in buffer $\mathrm{B}: 30 \mathrm{mM}$ HEPES/ $\mathrm{NaOH}$ (pH 7.4) containing $0.25 \mathrm{~m} M$ EGTA, 1 $\mathrm{mM} \mathrm{NaH} \mathrm{PO}_{4}$, and $1 \mathrm{mM}$ ATP, or in buffer C: $30 \mathrm{~m} M$ HEPES/NaOH (pH 7.4) containing $0.25 \mathrm{~m} M$ EGTA. Incubations were in a $250-500 \mu \mathrm{l}$ volume and were terminated by the addition of $1.5 \mathrm{ml}$ of chloroform-methanol (1:2 by vol). The tubes were kept on ice for 15-60 min before further extraction of the lipids. Protein was determined spectrophotometrically, using bovine serum albumin as standard (Geiger and Bessman, 1972).

\section{Analysis of the lipids}

Lipids were extracted under acidic solvent conditions (Van Rooijen et al., 1983). Separation was performed on Merck (Darmstadt) Silica G-60 plates, $20 \times 20 \times 0.025$ $\mathrm{cm}$ as follows: for polyphosphoinositide separations, lipids were applied to oxalated TLC plates (Van Rooijen et al., 1983). When DG was also to be studied, half of the lipid was conserved and separated on unoxalated plates with hexane-ether (70:30, by vol). When PA and PI were investigated with regard to their unsaturation, lipid classes were first separated on TLC with chloroformmethanol-acetic acid- $\mathrm{H}_{2} \mathrm{O}$ (50:32:11:3, by vol). Labeled bands were located autoradiographically, scraped, and the lipids were extracted from the silica gel with acidified chloroform-methanol. The purified PI was spotted on $40 \%$ (wt/vol aq.) silver nitrate-impregnated TLC plates, and separated according to the degree of unsaturation (Holub and Kuksis, 1971) with chloroform-methanol- $\mathrm{H}_{2} \mathrm{O}$ ( $65: 35: 5$ by vol). The purified PA was methylated before argentation chromatography by incubation with excess diazomethane (De Boer and Backer, 1963) in capped tubes for 100-120 min at room temperature, in a final volume of $0.5 \mathrm{ml}$ of ether. The methylation reaction was terminated by evaporation of the ether and the diazomethane under a stream of nitrogen. The species of methylated PA were separated according to degree of unsaturation (Renkonen, 1968) on argentated plates with chloroform-methanol $(98: 2$, by vol). Bands were located autoradiographically, scraped, and scintillation counted.

\section{RESULTS AND DISCUSSION}

Stimulation of nerve endings with $10^{-3} \mathrm{M}$ carbamylcholine $(\mathrm{CCh})$ in the presence of ${ }^{32} \mathrm{P}_{\mathrm{i}}$ resulted in enhanced incorporation of radiotracer into PA and PI and could be blocked by $10^{-5} M$ atropine (Atr). In agreement with a previous report (Schacht and Agranoff, 1974), about $85 \%$ of the increase in labeled PI could be accounted for in the tetraenoic fraction (Table 1). Analysis of labeled PA from the same incubation showed that $74 \%$ of its increase could be accounted for in the tetraenoic fraction (Fig. 1). Although the less unsaturated bands appeared unaffected by the muscarinic stimulation, some enhancement of incorporation was seen in a slowly migrating band, very likely the hexaenoic species (Baker and Thompson, 1972). About 12$16 \%$ of the labeled material remained at the origin, and is presumed to contain nonmethylated PA or degradation products. Stimulated labeling of PA was also blocked by $10^{-5} M$ Atr.

When membranes prepared from ${ }^{32} \mathrm{P}$-prelabeled nerve endings were exposed to $\mathrm{Ca}^{2+}$, a loss of labeled PIP and PIP $_{2}$ was observed, with a concomitant increase in radiotracer recovered as the phosphodiesteratic degradation products inositol 1,4bisphosphate $\left(\mathrm{IP}_{2}\right)$ and $\mathrm{IP}_{3}$ (Fig. 2A). The total amount of radioactivity lost from the polyphosphoinositides in the presence of $\mathrm{Ca}^{2+}$ was recovered in the water-soluble fraction, although there was a disproportionately large amount of $\mathrm{IP}_{2}$ and a small amount of $\mathrm{IP}_{3}$. This difference can be explained by breakdown of about half of the $\mathrm{IP}_{3}$ to $\mathrm{IP}_{2}$ via the action of a phosphatase, and accumulation of the $\mathrm{IP}_{2}$. To detect the anticipated concomitant release of DG under these conditions, membranes were prepared from nerve endings labeled with $\left[{ }^{3} \mathrm{H}\right] \mathrm{glycerol}$, and incubated as described in the legend to Fig. $2 \mathrm{~A}$. In the absence of added $\mathrm{Ca}^{2+}$, $44,000 \mathrm{cpm}$ were recovered in the DG fraction, whereas in its presence $45,500 \mathrm{cpm}$ were recovered. Glycerol-labeled $\mathrm{PIP}_{2}$ decreased from 1,060 to 596 $\mathrm{cpm}$ and PIP from 4,430 to $2,200 \mathrm{cpm}$. Thus, a loss of about 2,700 may be accounted for in DG, but because of the high level of basal radioactivity, the result cannot be considered significant. No loss of labeled PI has been detected under conditions of phosphodiesteratic degradation of the polyphos-

TABLE 1. Effect of CCh on the species of PI labeled

\begin{tabular}{lcc}
\hline & Tetraene band & $\begin{array}{c}\text { Other bands } \\
\text { summed }\end{array}$ \\
\hline Control & $383 \pm 23$ & $457 \pm 33$ \\
CCh & $903 \pm 17$ & $551 \pm 18$ \\
CCh + Atr & $389 \pm 19$ & $449 \pm 34$ \\
\hline
\end{tabular}

Radiotracer recovered from the tetraenoic and other species of PI in nerve endings incubated with $\mathrm{CCh}$ and Atr (see legend to Fig. 1). 


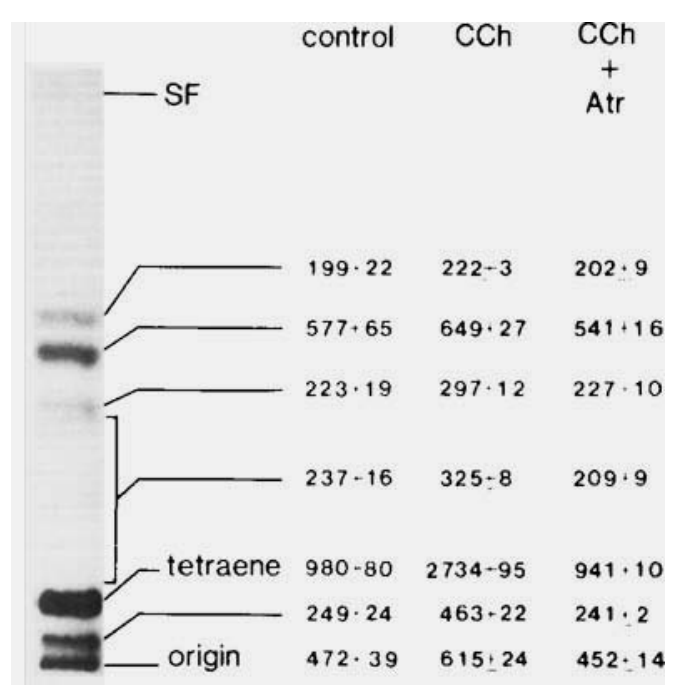

FIG. 1. Effect of carbamylcholine on the species of PA labeled. Nerve endings were incubated as described in the text, in the presence of $10^{-3} \mathrm{M}$ CCh and $10^{-5} \mathrm{M}$ Atr, as indicated. The autoradiographic pattern of the separation on argentation TLC is a CCh-stimulated preparation typical of three independent experiments. The band marked "tetraene" comigrated with authentic 1-stearoyl, 2$\left[1-{ }^{14} \mathrm{C}\right]$ arachidonoyl-sn-glycerol-3-phosphate, which was prepared by incubation of the labeled phosphatidylcholine (Amersham) with phospholipase D. SF is solvent front. Values are expressed as $\mathrm{cpm}( \pm \operatorname{SEM}, \mathrm{n}=3)$ recovered from the various bands.

phoinositides (Van Rooijen et al., 1983). An alternative approach for detecting the released DG was to add $\left[\gamma-{ }^{32} \mathrm{P}\right] \mathrm{ATP}$ to an incubation of unlabeled membranes in the presence or absence of $\mathrm{Ca}^{2+}$. The

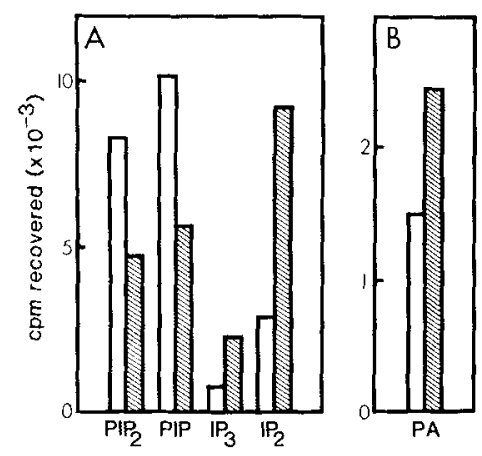

FIG. 2. Diesteratic degradation of the polyphosphoinositides and resynthesis of PA in nerve ending membranes. Nerve ending membranes were incubated in the absence (open bars) or presence (hatched bars) of $1.5 \mathrm{mM}$ of $\mathrm{Ca}^{2+}$, to observe the appearance of ${ }^{32} \mathrm{P}$-labeled inositol phosphates (A) or newly formed ${ }^{32}$ P-labeled PA (B). A: Following preincubation for $15 \mathrm{~min}$ in bulk, ${ }^{32} \mathrm{P}$-prelabeled nerve ending membranes were incubated in duplicate in a final volume of 250 $\mu l$ of buffer B. Polyphosphoinositides were analyzed as described in the text. Radiotracer recovered as the inositol phosphates, $I P_{2}$ and $I P_{3}$, was established following separation on high-voltage paper electrophoresis (Van Rooijen et al., 1983). B: Unlabeled nerve ending membranes were incubated with [ $\gamma^{-32}$ P]ATP as described in the legend to Fig. 3. The values given are total radiotracer recovered in bands shown in Fig. 3

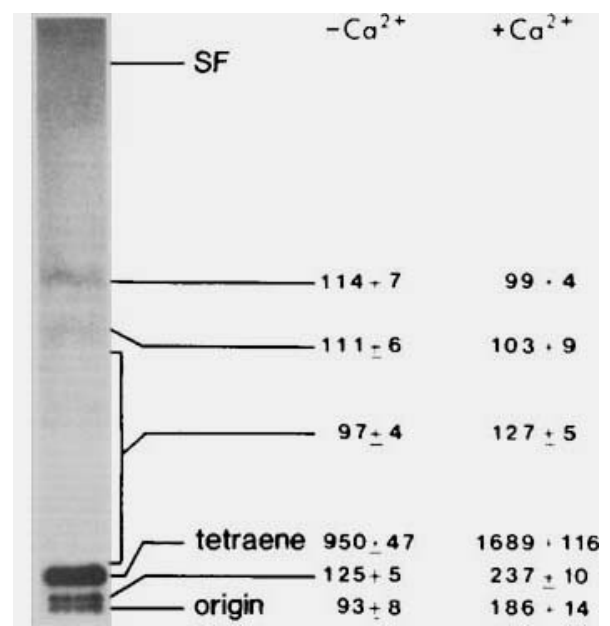

FIG. 3. Stimulation of the diesteratic degradation of the polyphosphoinositides and the species of PA formed in nerve ending membranes. Unlabeled nerve ending membranes were incubated with $1 \mathrm{mM} \mathrm{Mg}^{2+}$ and $1 \mathrm{mM}\left[\gamma^{-32}\right.$ P]ATP (Amersham, diluted to $28 \mathrm{Ci} / \mathrm{mol}$ ) in the absence $(-)$ or presence $(+)$ of $1.5 \mathrm{mM} \mathrm{Ca}^{2+}$, for $5 \mathrm{~min}$, in a final volume of $250 \mu$ l of buffer $\mathrm{C}$. The autoradiographic pattern of the separation on argentation TLC is of $\mathrm{Ca}^{2-}$ stimulation and is typical of two experiments (see legend to Fig. 1).

released DG is converted to $\left.{ }^{32} \mathrm{P}\right] \mathrm{PA}$ and can thus be detected (Figs. 2B and 3). The amount of PA formed, calculated on the basis of the specific activity of the added ATP, was $15 \mathrm{pmol}$.

Comparison of the profile of PA obtained in intact nerve endings with that seen in $\left[{ }^{32} \mathrm{P}\right] \mathrm{ATP}$-incubated membranes shows significant differences. Whereas in unstimulated nerve endings $33 \%$ of the labeled PA is of the tetraenoic species (Fig. 1), in the unstimulated nerve ending membrane preparation $64 \%$ of the labeling of PA can be accounted for by its tetraenes (Fig. 3). This difference can be explained by the fact that in membranes PA stems only from labeling of released DG, whereas in nerve endings, PA labeling reflects both the inositide labeling cycle and de novo synthesis. Since arachidonate is believed to enter the inositides at a step subsequent to de novo synthesis via a deacylation-reacylation mechanism, we can assume that de novo labeling of the tetraenoic species is low. This is seen as a relatively smaller percentage of tetraenoic species in the nerve endings than in the membranes. However, as stated above, most of the CCh-enhanced labeling of PA is found in its tetraenoic species, indicating that $\mathrm{CCh}$ stimulates mainly the operation of the inositide cycle, rather than de novo synthesis of PA. Similarly in $\mathrm{Ca}^{2+}$-stimulated nerve ending membranes, $78 \%$ of the enhanced labeling of PA could be accounted for by tetraenoic species. Implicit in these conclusions is that the DG moiety remains intact during the stimulated cycle. It is also noteworthy that lysoinositides were not detected in nerve endings or in prelabeled membranes. Al- 
though these results do not definitively rule out the possibility that arachidonate is released during muscarinic stimulation of the inositide cycle in nerve endings, such release can at most be on a modest scale.

Acknowledgments: The research was supported by NIH grants NS 15413 and NS 08841.

\section{REFERENCES}

Aveldano M. I. and Bazan N. G. (1975) Rapid production of diacylglycerols enriched in arachidonate and stearate during early ischemia. $J$. Neurochem. 25, 919-920.

Baker R. R. and Thompson W. (1972) Positional distribution and turnover of fatty acids in phosphatidic acid, phosphoinositides, phosphatidylcholine and phosphatidylethanolamine in rat brain in vivo. Biochim. Biophys. Acta 270, 489-503.

Banschbach M. W., Geison R. L., and Hokin-Neaverson M. (1981) Effect of cholinergic stimulation on levels and fatty acid composition of diacylglycerols in mouse pancreas. Biochim. Biophys. Acta 663, 34-45.

Bazan N. G. (1970) Effects of ischemia and electroconvulsive shock on free fatty acid pool in the brain. Biochim. Biophys. Acta 218, 1-10.

Bell R. L., Kennerly D. A., Stanford N., and Majerus P. W. (1979) Diglyceride lipase: a pathway for arachidonate release from human platelets. Proc. Natl. Acad. Sci. 76, $3238-3241$.

Berridge M. J. (1983) Rapid accumulation of inositol trisphosphate reveals that agonists hydrolyze polyphosphoinositides instead of phosphatidylinositol. Biochem. J. 212, 849-858.

Billah M. M., Lapetina E. G., and Cuatrecasas P. (1981) Phospholipase $\mathrm{A}_{2}$ activity specific for phosphatidic acid. A possible mechanism for the production of arachidonic acid in platelets. J. Biol. Chem. 256, 5399-5403.

Broekman M. J., Ward J. W., and Marcus A. J. (1980) Phospholipid metabolism in stimulated platelets. Changes in phosphatidylinositol, phosphatidic acid and lysophospholipids. J. Clin. Invest. 66, 275-283.

Broekman M. J., Ward J. W., and Marcus A. J. (1981) Fatty acid composition of phosphatidylinositol and phosphatidic acid in stimulated platelets. J. Biol. Chem. 256, 8271-8274.

De Boer T. J. and Backer H. J. (1963) p-Tolylsulfonylmethylnitrosamide. Org. Synth. Coll. IV, 943-946.

Fisher S. K., Van Rooijen L. A. A., and Agranoff B. W. (1984) Renewed interest in the polyphosphoinositides. Trends Biochem. Sci. 9, 53-56.

Geiger P. J. and Bessman S. P. (1972) Protein determination by Lowry's method in the presence of sulphydryl reagents. Anal. Biochem. 49, 467-473.

Holub B. J. and Kuksis A. (1971) Resolution of intact phosphatidylinositol by argentation thin-layer chromatography. $J$. Lipid Res. 12, 510-512.

Keough K. M. W., MacDonald G., and Thompson, W. (1972) A possible relation between phosphoinositides and the diglyceride pool in rat brain. Biochim. Biophys. Acta 270, 337-347.

Kerr S. E. and Read W. W. C. (1963) The fatty acid components of polyphosphoinositides prepared from calf brain. Biochim. Biophys. Acta 70, 477-478.

Lapetina E. G., Billah M. M., and Cuatrecasas P. (1981) The phosphatidylinositol cycle and the regulation of arachidonic acid production. Nature 292, 367-369.

Marion J. and Wolfe L. S. (1979) Origin of the arachidonic acid released post-mortem in rat forebrain. Biochim. Biophys. Acta 574, 25-32.

Renkonen O. (1968) Mono- and dimethylphosphatidates from different subtypes of choline and ethanolamine glycerophosphatides. Biochim. Biophys. Acta 152, 114-135.

Rittenhouse-Simmons S. (1980) Indomethacin induced diglyceride accumulation in activated human platelets. $J$. Biol. Chem. 255, 2259-2262.

Schacht J. and Agranoff B. W. (1974) Stimulation of hydrolysis of phosphatidic acid by cholinergic agents in guinea pig synaptosomes. J. Biol. Chem. 249, 1551-1557.

Van Rooijen L. A. A., Seguin E. B., and Agranoff B. W. (1983) Phosphodiesteratic breakdown of endogenous polyphosphoinositides in nerve ending membranes. Biochem. Biophys. Res. Commun. 112, 919-926.

Wolfe L. S. (1982) Eicosanoids: prostaglandins, thromboxanes, leukotrienes, and other derivatives of carbon-20 unsaturated fatty acids. J. Neurochem. 38, 1-14. 